\title{
¿VES LO QUE DIBUJAS? \\ OBSERVANDO CÉLULAS CON EL MICROSCOPIO
}

\author{
DÍAZ DE BUSTAMANTE, J. y JIMÉNEZ ALEIXANDRE, M.P. \\ Departamento Didáctica de las Ciencias Experimentales. Universidad de Santiago de Compostela.
}

\section{SUMMARY}

The difficuities which Secondary School and University students encounter when looking at cell samples through the microscope are explored in this paper. Students were asked to draw what they expected to see, and later to draw what they did see while performing a Laboratory activity in a classroom situation. The drawings are analysed and categorised. Some of the causes of these difficulties are discussed.

\section{INTRODUCCIÓN}

\section{Interpretación de imágenes en biología}

Cualquier libro de texto de ciencias contiene multitud de representaciones icónicas de distinto tipo. En los textos de biología una gran parte de estas representaciones corresponden a fotografías, dibujos o esquemas que representan toda la gama imaginable de escalas, seccio. nes e idealizaciones de los seres vivos, de sus estructuras o de sus componentes y proponen la realización de activiđades prácticas que incluyen la observación directa o microscópica de muestras. No comprenderíamos hoy en día la enseñanza y el aprendizaje de la biología $\sin$ recurrir a unos y a otras.

La percepción visual se ha estudiado en psicología (Gordon, 1989) bajo multitud de enfoques y ha originado numerosas teorías al respecto. Las condiciones de investigación, muy estrictas en el control de variables, provocan que sea imposible aplicar normalmente sus metodologías a las condiciones de aula, e incluso establecer comparaciones basándose en sus descubrimientos.

Teniendo en cuenta que los alumnos tienen problemas a la hora de interpretar y plasmar en dibajos sus observaciones, o al interpretar, observar o percibir las represen. taciones icónicas de los textos, ya señalados por Hodson (1986) y constatado de forma empírica por los profesores de biología, sorprende que, al buscar en bases biblio- gráficas o revisiones en las principales revistas, aparezcan relativamente pocos trabajos sobre la interpretación de observaciones referidos a aspectos concretos de la biología.

En ocasiones, para el análisis de tareas en biología, se han utilizado, por un lado, algunos postulados básicos de la teoría de la Gestalt correspondientes al fenómeno figura-fondo -según el cual (Luna Blanco, 1992) las figuras tienen forma que proceden de sus contornos, están localizadas frente al fondo y se conectan más fácilmente con significados, mientras que con el fondo sucede lo contrario, organizándose respectivamente figura y fondo en áreas envueltas y envolventes, convexas y cóncavas, con simetría vertical y orientaciones vertical y horizontal o si ella-. Por otro lado también se han utilizado algunos postulados de la teoría de reconocimiento de patrones, que en su formulación más simple (Fuentes Melero, 1992) implicaría que almacenado en la memoria existe un modelo o patrón con el que se compararía la forma que se ha de reconocer, y en forma más complicada correspondería al análisis e identificación no de la forma en su conjunto, sino de sus características geométricas, líneas rectas, ángulos y líneas curvas. Así, en los trabajos MacNab, Hansell y Johnstone (1991), se analiza la destreza de identificar figuras ocultas en un 
fondo distractor y la extracción de información relevante válida para ser aplicada en diferentes contextos, y en los de Reid y Miller (1980) sobre destrezas en la observación de fotografías, y Reid (1990a) de dibujos.

En estos y otros trabajos, como en Reid (1984, 1990b), se estudian el papel del color y de otros parámetros importantes en la construcción de ilustraciones, aspectos sobre la transmisión de información, recuerdo de su contenido visual y estudio del efecto de superioridad de Ios dibujos. En Russell-Gebbett (1984, 1985), Macnab y Johnstone (1990), y Macnab, Hansell y Johnstone (1991) se investigan destrezas espaciales y estrategias en la percepción de estructuras tridimensionales. El desarrollo de las destrezas de observación, registro e interpretación en biología, orientados a los exámenes prácticos externos del Advanced GCE en Gran Bretaña, es abordado por Garvin y Boyd (1990) mediante la propuesta de una serie de técnicas. Los dibujos han sido utilizados en el estudio de las concepciones de los estudiantes sobre aspectos como la organización del aparato digestivo, la respiración de los peces y la germinación de la habichuela (Giordan, 1982) o las relaciones estructura-función (Caravita y Tonucci, 1987). Sin embargo, ninguno de estos trabajos aborda el estudio de las destrezas de interpretación de estructuras biológicas en el contexto de las clases prácticas y los problemas que existen para su adquisición y evaluación en diferentes niveles educativos.

Abordamos aquí las destrezas de observación microscópica de células por parte de alumnos de secundaria y magisterio. Los aspectos que tratamos se refieren al grado de precisión y de fidelidad con que plasman sus observaciones, referidos a morfología celular y organización tisular. Paralelamente, se ha investigado la idea de célula que como objeto tridimensional tiene cada alumno (Jiménez y Díaz, 1993; Díaz et al, 1993), además, se ha registrado en vídeo y se ha analizado la actividad desarrollada durante las prácticas por algunos de ellos.

\section{METODOLOGÍA}

\section{Cuestiones investigadas}

Se han investigado dos aspectos principales:

A. ¿Qué ideas previas tienen los alumnos sobre el tipo de muestra que van a observar?

B. ¿Qué interpretación hacen de las imágenes microscópicas que observan? Particularmente,

B1. ¿reproducen en sus dibujos la morfología de diferentes tipos de células?;

B2. ¿representan las estructuras visibles?

Algunos aspectos previstos inicialmente como el tamaño y la profundidad de carmpo resultaron tan complejos que son objeto de otro trabajo específico.

\section{Muestra}

Han intervenido 7 grupos de $1^{\circ}$ y $3^{\circ}$ de BUP y $2^{\circ}$ de magisterio (especialidad de ciencias), con un total do 199 alumnos. La elección de los grupos se debe a la colaboración del profesorado que permitió la observación durante las prácticas.

La muestra de $1^{\circ}$ de BUP está formada por los 52 estudiantes de un instituto de una pequeña localidad, de 14-15 años, y la muestra de $3^{\circ}$ de BUP está formado por 107 alumnos de un instituto de una pequeña ciludad, con edades de 16-17 años; en ambos casos la mitad son chicos y la otra mitad chicas. La muestra de magisterio consta de 40 alumnos y sus edades oscilan entre los 19 20 años; la proporción de chicas es mayor que la de chicos (2/3 chicas). Al haberse realizado el muestren on dos sesiones sucesivas, el número de alumnos que ha completado cada tarea es indicado en la tabla correspondiente.

Todos ellos han estudiado en cursos anteriores el tema correspondiente a la organización celular $y$, salvo en el caso de los estudiantes de $1^{\circ}$ de BUP que no nos consta explícitamente, los demás han realizado prácticas de laboratorio de observación de células en otros cursos.

\section{Instrumento de investigación}

La investigación se lleva a cabo durante prácticas convencionales de laboratorio, realizadas con su profesor o profesora y dentro de la marcha normal de las asignatu. ras procurando que las interferencias fuesen minimas, lo que conlieva que las prácticas analizadas sean las que cada profesor había programado, y, por tanto, no son las mismas en todos los casos. En las tablas se señala para cada práctica el número concreto de estudiantes que la completó.

Las prácticas consideradas corresponden a la observación y estudio microscópico de epidermis de cebolla $\left(1^{\circ}\right.$ de BUP y $2^{\circ}$ de magisterio) y de epitelio de la mucosa bucal ( $3^{\circ}$ de BUP y $2^{\circ}$ de magisterio), que incluyen tinción con azul de metileno, y epidermis de hoja de lírio $\left(3^{\circ}\right.$ de BUP) en la que no se tiñe la muestra. Cada sesión en $1^{\circ}$ y $3^{\circ}$ de $B U P$, cuya duración era de unos 50 minutos, fue realizada por un grupo de tres o cuatro (raramente cinco) alumnos por microscopio. En $2^{\circ}$ de magisterio la duración de cada sesión de prácticas fue de 2 horas, disponiendo de un microscopio cada dos alumnos. En todos los casos asistieron entre 20 y 30 alumnos por sesion. Los microscopios fueron revisados previamente por uno de los autores, para comprobar sus adecuadas condiciones operativas.

Para su desarrollo, se suministró a los alumnos un guión de cada práctica. En $1^{\circ}$ de BUP y $2^{\circ}$ de magisterio se les pidio que hicieran, en primer lugar, dos dibujos, uno a menor aumento (x40) y otro a mayor aumento ( $x 400)$, derallando aquello que esperaban o recordaban que iban a observar; y, en segundo lugar, después de la observación, otros dos dibujos de lo que habían observado a 
similares aumentos. En $3^{\circ}$ de BUP sólo hicieron el dibujo de lo observado a mayor aumento.

Reproducimos a continuación el tex to correspondiente a la tarea en $1^{\circ}$ de BUP y $2^{\circ}$ de magisterio:

- Dibuja lo mejor que puedas el aspecto que crees que tendrá la muestra de pocos aumentos $(x 40)$, procurando que resulte claro y comprensible. Describe todos aquelios aspectos que te parezcan importantes.

- Dibuja lo mejor que puedas el aspecto que crees que tendrá la muestra de muchos aumentos $(\mathrm{x} 400)$, procurando que resulte claro y comprensible. Describe todos aquellos aspectos que te parezcan importantes.
- Dibuja lo mejor que puedas el aspecto que tiene la muestra de pocos aumentos ( $\mathrm{x} 40$ ), procurando que resulte claro y comprensible. Describe todos aquellos aspectos que te parezcan importantes.

- Dibuja lo mejor que puedas el aspecto que tiene la muestra de muchos aumentos $(x 400)$, procurando que resulte claro y comprensible. Describe todos aqueflos aspectos que te parezcan importantes.

Simultáneamente se grabaron en vídeo algunas de las sesiones, lo que permite analizar aspectos como el comportamiento de los estudiantes, sus interacciones, el tiempo real de observación, etc., todo lo cual será objeto de otro trabajo.

Tabla I

Representación de células de epidermis de cebolla a x400 aumentos antes de realizar la observación. (C=representación previa de una cebolla).

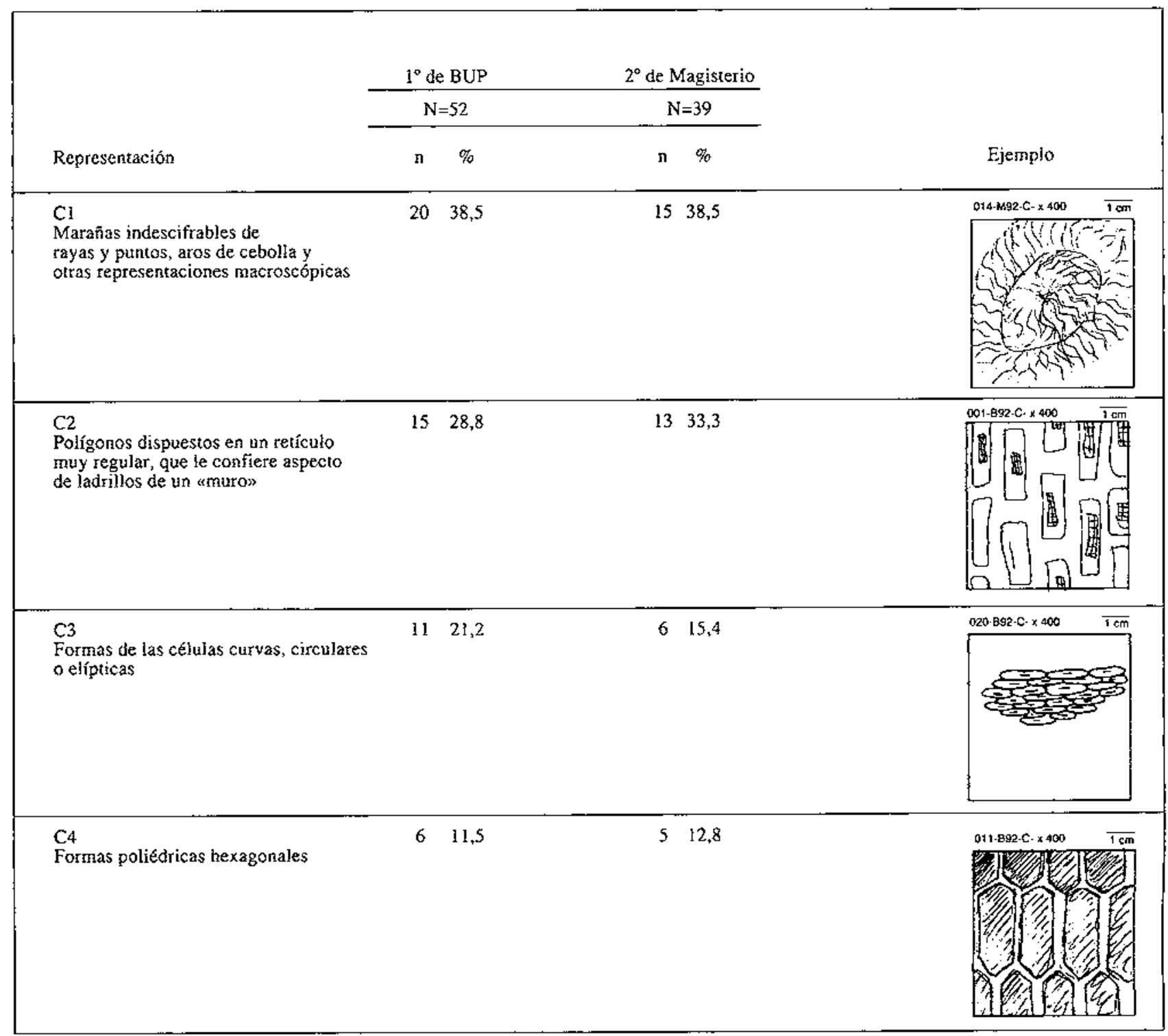




\section{Análisis de los dibujos}

El análisis se orientó hacia la respuesta de las cuestiones planteaclas. Comprende la revisión de todos los dibujos, -cerca de un millar-, realizados por los alumnos y el establecimiento posterior de categorías generales, agrupándolos según su similitud morfologica, de distribución y de detalle para los distintos tipos celulares. Algu. nos dibujos, considerados representativos de cađä categoría, se presentan como ejemplos ilustrativos.

\section{RESULTADOS}

\section{Cómo dibujan las cétulas}

Indicaremos y discutiremos sucesivamente los resultados obtenidos para cada una de las cuestiones investigadas.

\section{Dibujos de las muestras de epidermis de cebolla antes de la observación}

Los resultados del análisis de los dibujos realizados por los estudiantes de $1^{\circ}$ de BUP y de $2^{\circ}$ de magisterio de su idea previa, la «imagen mental», de las muestras que posteriormente observarían, se presentan en las tablas I y II. Corresponden a epidermis de cebolla y, aunque fueron realizados teóricamente a $\times 40$ y x 400 aumentos, resultaron similares en casi todos los aspectos; por ello nos referiremos a Ios dibujos realizados a $\times 400$ aumentos.

En general, la idea que los alumnos tienen sobre el aspecto de las células de epidermis de cebolla se encuentra bastante alejada de la realidad (Tabla I). Más de un tercio, en ambos cursos, se la imaginan con el aspecto que recuerdan de la cebolla, dibujando Ios «aros» típicos de la cebolla o representando marañas indescifrables de rayas y puntos. Este tipo de dibujos han sido denominados $\mathrm{C} 1$, y se diferencian claramente de los demás.

La segunda categoría de dibujos corresponde a la que hemos denominado $\mathrm{C} 2$, con aspecto de «muro»; las células son dibujadas como ladrillos de un muro o en un retículo muy simétrico. Este tipo es más frecuente en $2^{\circ}$ de magisterio - un tercio del total-, que en $1^{\circ}$ de BUP -que supone poco más de la cuarta parte.

La tercera categoría, que hemos denominado $\mathrm{C}^{3}$, es la más difícil de establecer. Incluye todos aquellos casos en que dominan las líneas curvas, circulares o elípticas. Su frecuencia es bastante alta en ambos cursos, alcanzando el $21,2 \%$ en $1^{\circ}$ de BUP.

La cuarta y última categoría, $\mathrm{C} 4$, hexagonales, incluye todas aquellas representaciones de células con tal forma y que, en ocasiones, recuerdan panales de abeja. Su frecuencia es la menor en ambas muestras.

En la tabla If se indican los elementos que dibujan en estas células, destacando que, a menores aumentos (x40), un $40 \%$ de los alumnos representa exclusivamente los contornos de las células que nosotros interpretamos como la pared celular. A $\times 400$ aumentos, lo más frecuente es que representen la pared y el núcleo (tal como aparece en el ejemplo de células tipo C3), y que supone más de la mitad de los casos en magisterio; sólo unos pocos de estos alumnos representaron pared, núcleo y nucleolo(s) en las células. La proporción de dibujos en los que no es posible reconocer estas estructuras es bastante elevado en los dos grupos y para todos los aumentos.

Tabla II

Elementos celulares representados en dibujos de epidermis de cebolla antes de realizar la observación.

\begin{tabular}{|c|c|c|c|c|c|c|c|c|}
\hline \multirow[b]{3}{*}{ Elementos } & \multicolumn{4}{|c|}{$1^{\circ}$ de BUP } & \multicolumn{4}{|c|}{$2^{\circ}$ de Magisterio } \\
\hline & $x 40$ & $N=52$ & $x 400$ & $\mathrm{~N}=52$ & $\times 40$ & $\mathrm{~N}=39$ & $x 400$ & $N=39$ \\
\hline & $\mathrm{n}$ & $\%$ & $\mathrm{n}$ & $\%$ & $\mathrm{n}$ & $\%$ & $\mathrm{n}$ & $\%$ \\
\hline Pared & 21 & 40,4 & 16 & 30,8 & 14 & 35,9 & 8 & 20,5 \\
\hline Pared y núcleo & 8 & 15,4 & 16 & 30,8 & 10 & 25,6 & 20 & 51,3 \\
\hline Pared, núcleo y nucleolos & 0 & 0,0 & 0 & 0,0 & 0 & 0,0 & 3 & 7,7 \\
\hline No reconocibles & 23 & 44,2 & 20 & 38,5 & 15 & 38,5 & 8 & 20,5 \\
\hline
\end{tabular}




\section{Interpretación de las imágenes microscópicas que observan}

Las cuestiones relativas a la interpretación de imágenes microscópicas han sido abordadas en el análisis de los dibujos que realizaron mientras observaban muestras correspondientes a: epidermis de cebolla, en los grupos de $1^{\circ}$ de BUP y magisterio; epidermis de hoja de lirio, en $3^{\circ}$ de BUP; y epitelio bucal, en $3^{\circ}$ de BUP y magisterio (Tablas III, IV, V, VI, VII y VIII). Como en el caso anterior, los dibujos realizados a partir de diferentes aumentos fueron morfológicamente muy semejantes y utilizaremos fundamentalmente los correspondientes a los máximos aumentos.
Abordamos primero la cuestión referente a la reproducción en los dibujos de la morfología de los diferentes tipos celulares.

\section{Dibujos de epidermis de cebolla}

El análisis de los dibujos a 400 aumentos nos ha llevado a establecer, en el caso de la epidermis de cebolla con alumnos de $1^{\circ}$ de BUP y magisterio, cuatro categorías (Tabla III), siendo las tres primeras similares en casi todo a las establecidas para los dibujos previos a la observación, y la cuarta (OC4) incluyendo aquellos

Representación de observaciones de epidermis de cebolla a x400 aumentos (OC=representación observación de una cebolla).

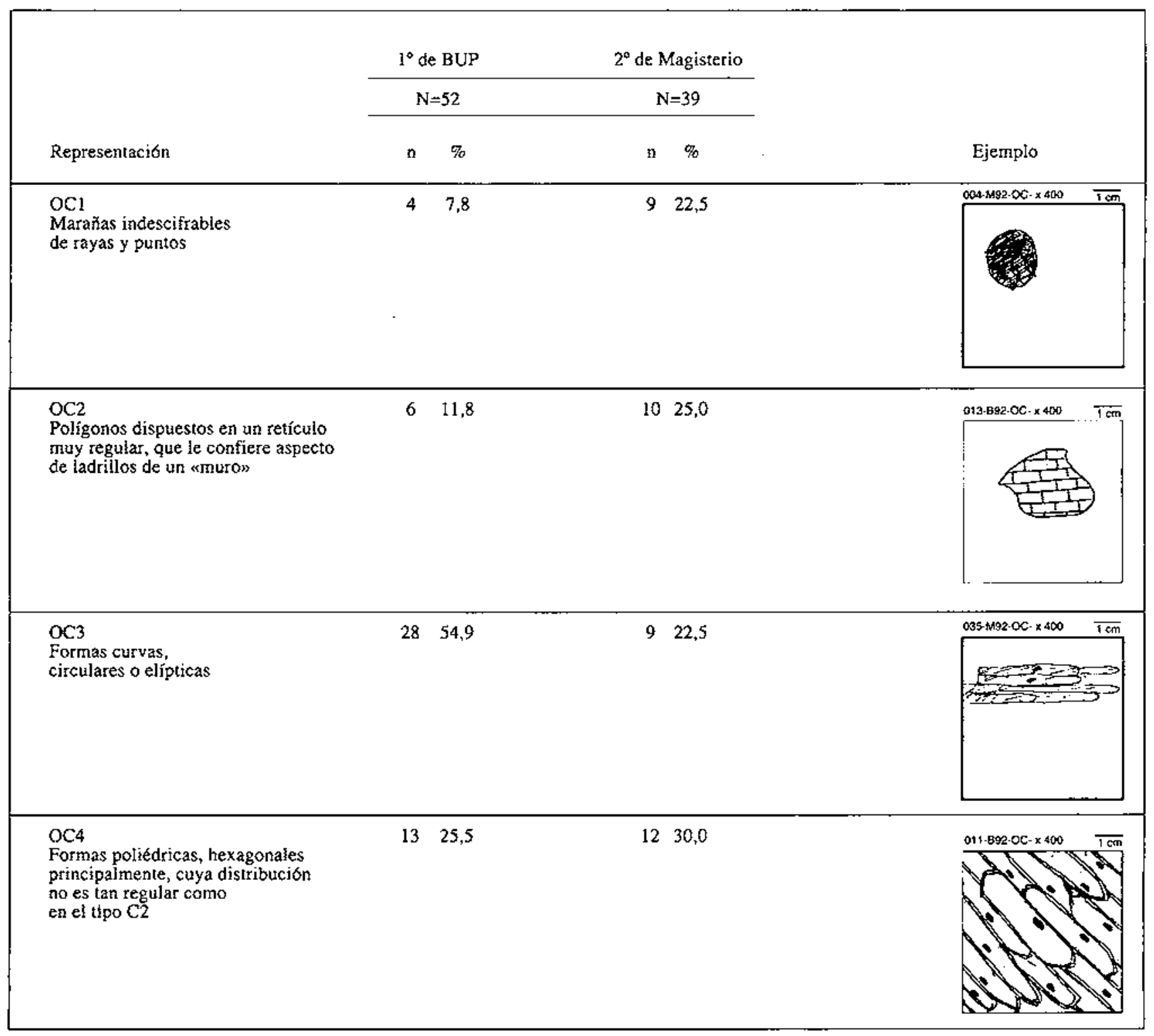


casos en los que las células aparecen con forma desde hexagonal hasta rectangular. La frecuencia de aparicion de unas y otras nos causó inicialmente cierta sorpresa, ya que, en magisterio, el $22,5 \%$ de los estudiantes realizaron dibujos de tipo OCl, irregulares y sin casi relación con to esperado y con una frecuencia similar a la de los otros tres tipos, siendo también notable la permanencia de algo más de un $25 \%$ en representaciones OC2 con aspecto de «muro». La representación más frecuente fue el tipo OC 3 , ovaladas, con el $54,9 \%$ en $1^{\circ}$ de BUP, y el tipo OC4, con el $30 \%$ en magisterio. En conjunto, tos tipos OC3 y OC4, que corresponden a la mejor descripción de las muestras, supone el $80,4 \%$ en $1^{\circ}$ de BUP mientras que en magisterio sólo aparecen en el $52,5 \%$.

Tabla IV

Representación de células de epidermis de hoja de lirio. $3^{\circ}$ de $B U P(x 400, N=103$; OL=representación de la observación de un lirio)

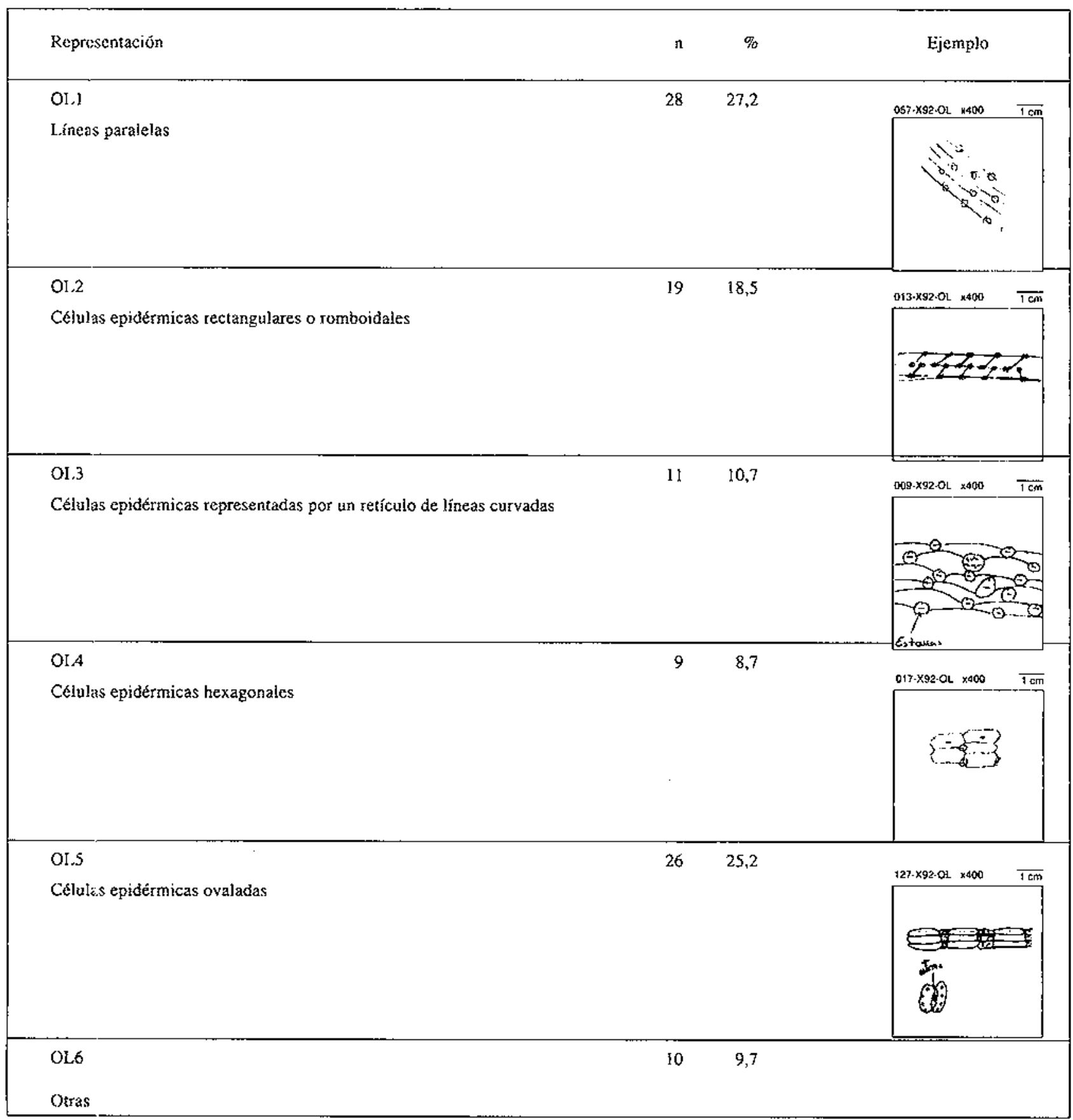


Tabla V

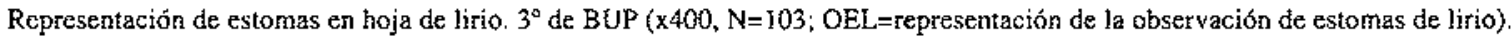

\begin{tabular}{|c|c|c|c|}
\hline Representacion & $\mathrm{n}$ & $\%$ & Ejemplo \\
\hline OEL1 & 28 & 27,2 & $057 \times \times 92.0 \mathrm{~L} \times 4000$ \\
\hline $\begin{array}{l}\text { Líneas paralelas } \\
\text { Circulares }\end{array}$ & & & \\
\hline OEL2 & 10 & 9,7 & $025 . \times 92-0 L \times 400$ \\
\hline OELL3 & $1 !$ & 10,7 & $003 . \times 92.01 \times 400$ \\
\hline OEL4 & 6 & 5,8 & $0.77 . \times 92-0 \mathrm{LL} \times 400$ \\
\hline OEL5, & 4 & 3,9 & $013 \times 992.02 \times 400$ \\
\hline OHLL6 & 9 & 8,7 & 127.X92.0L $\times 400$ \\
\hline $\begin{array}{l}\text { OEL7 } \\
\text { No representan estomas }\end{array}$ & 35 & 34,0 & \\
\hline
\end{tabular}


Tabla VI

Representación de células de epitelio bucal observadas a máximos aumentos. $3^{\circ}$ de BUP y $2^{\circ}$ de Magisterio $(\mathrm{OE}=$ representación de la observación de epitelio).

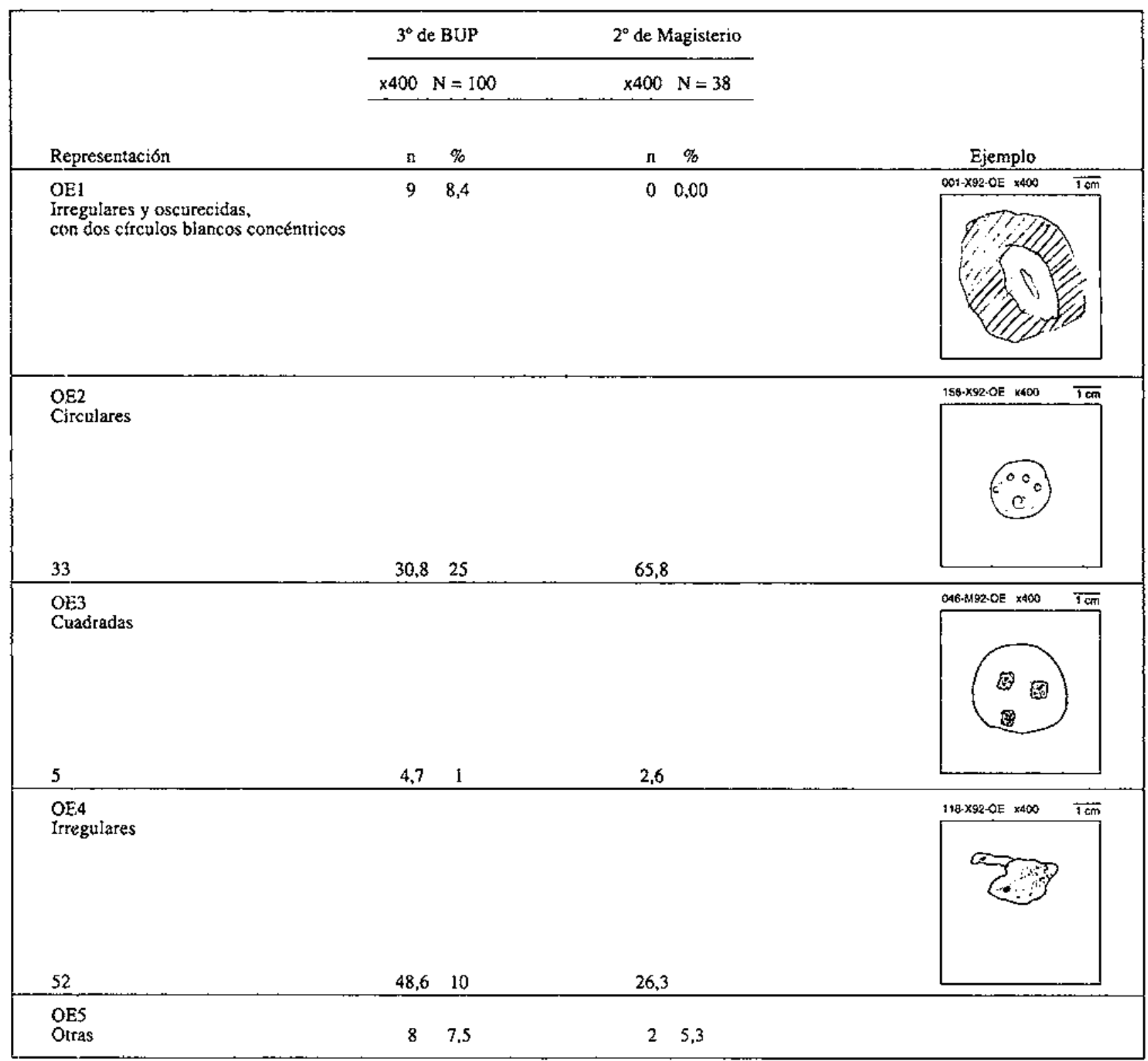

\section{Dibujos de epidermis de hoja de lirio}

Hemos agrupado Ios dibujos de epidermis de hoja de lirio realizados por los estudiantes de $3^{\circ}$ de BUP en seis categorías para la representación de las células epidérmicas (Tabla IV), y en siete categorías para los estomas (Tabla V). En este caso destaca lo disperso de la distribución entre las diferentes categorías de dibujos de células epiđérmicas, que es máximo, con el $27,2 \%$ para la categoría OL1, líneas paralelas, y mínimo para la categoría OLA, células epidérmicas hexagonales, con
$8,7 \%$. En el caso de los estomas, las categorías OEL1, estomas circulares, con el $27,2 \%$ y OEL 7 , sin estomas, con el $34 \%$ concentran más de la mitad.

\section{Dibujos de epitelio bucal}

Los dibujos correspondientes a las observaciones a $\times 400$ aumentos de epitelio bucal realizado por los estudiantes de $3^{\circ}$ de BUP y magisterio han sido agrupados en cinco categorias, que se reproducen en la tabla VI. Destacan 
por su frecuencia las categorías $\mathrm{OE} 2$ y $\mathrm{OE} 4$, que corresponden en el primer caso a representaciones de células circulares $y$, las segundas, a representaciones celulares irregulares, normalmente lobuladas, que ofrecen una calidad que entendemos mejor que la mayoría de los dibujos de células vegetales. En $3^{\circ}$ de BUP estas categorías presentan frecuencias del $30,8 \%$ (OE2) y el $48,6 \%$ (OE4), mientras que en magisterio son del $65,8 \%$ y el $26,3 \%$ respectivamente. El resto de las categorías de las representaciones son muy escasas, no alcanzando en ningún caso el 10\%; se incluyen en el tipo OE3 las representaciones de forma cuadrada, en $\mathrm{OE} 1$ las que son irregulares y se representan oscurecidas, con círculos blancos concéntricos interiores, y en OES se incluyen otras formas, líneas onduladas abiertas, borrones... que no han podido asociarse a ninguna de las anteriores al no poder identificar elementos celulares.

\section{Representación de las estructuras visibles}

Los resultados sobre la representación de las estructuras visibles, correspondientes a la segunda y última subcuestión, se presentan en las tablas VII y VIII.

La cantidad de estructuras que representan y la calidad con que lo hacen es sensiblemente mayor en este caso que cuando dibujaban su idea previa a la observación. En

Tabla VII

Elementos celulares representados en dibujos de observaciones de epidermis de cebolla.

\begin{tabular}{|c|c|c|c|c|c|c|c|c|}
\hline \multirow[b]{3}{*}{ Elementos } & \multicolumn{4}{|c|}{$1^{\circ}$ de BUP } & \multicolumn{4}{|c|}{$2^{\circ}$ de Magisterio } \\
\hline & $\times 40$ & $\mathrm{~N}=5 !$ & $\times 400$ & $\mathrm{~N}=51$ & $x 40$ & $N=40$ & $\times 400$ & $\mathrm{~N}=40$ \\
\hline & $\mathrm{n}$ & $\%$ & $\mathrm{n}$ & $\%$ & $\mathrm{n}$ & $\%$ & n & $\%$ \\
\hline Pared & 62,7 & 12 & 23,5 & 34 & 85,0 & 19 & 47,5 & \\
\hline Con pared y núcleo & 18 & 35,3 & 35 & 68,6 & 5 & 12,5 & 11 & 27,5 \\
\hline $\begin{array}{l}\text { Con pared, núcleo } \\
\text { y nucleoios }\end{array}$ & 0 & 0,0 & 3 & 5,9 & 0 & 0,0 & 9 & 22,5 \\
\hline No reconocibles & 1 & 2,0 & I & 2,0 & 1 & 2,5 & I & 2,5 \\
\hline
\end{tabular}

Tabla VIII

Elementos celulares representados en dibujos de observaciones de epitelio.

\begin{tabular}{|c|c|c|c|c|}
\hline \multirow[b]{3}{*}{ Elementos } & \multicolumn{2}{|c|}{$3^{\circ}$ de BUP } & \multicolumn{2}{|c|}{$2^{\circ}$ de Magisterio } \\
\hline & $\times 400$ & $N=107$ & $\times 400$ & $\mathrm{~N}=38$ \\
\hline & $\mathrm{n}$ & $\%$ & $\mathrm{n}$ & $\%$ \\
\hline Sólo la membrana & 24 & 22,4 & 5 & 13,2 \\
\hline Con membrana y nácleo & 54 & 50,5 & 13 & 34,2 \\
\hline $\begin{array}{l}\text { Con membrana, núcleo } \\
\text { y estructuras } \\
\text { citoplasmáticas }\end{array}$ & 11 & 10,3 & 14 & 36,8 \\
\hline No reconocibles & 18 & 16,8 & 6 & 15,8 \\
\hline
\end{tabular}

los dibujos de epidermis de cebolla encontramos (Tabla VII) que, a bajos aumentos $(x 40)$, la mayoría de las estructuras representadas corresponden a la pared celılar eI $62,7 \%$ en $1^{\circ}$ de BUP y el $85,0 \%$ en magisterio. A mayores aumentos $(\mathrm{x} 400)$, representan pared y núcleo una elevada proporción de estudiantes de BUP, el $68,6 \%$, inientras que sólo el $27,5 \%$ en magisterio hace lo mismo, y el $47,5 \%$ continúa representando exclusivamente la pared. Sin embargo, el $22,5 \%$ de los estudiantes de magisterio dibuja pared, núcleo y nucleolos. Respecto a los dibujos previos (Tabla II), prácticamente desaparecen los dibujos en que no es reconocible ninguna estructura.

En los dibujos de células de epitelio bucal (Tabla VIII) se indican las estructuras representadas, que fueron uno de los criterios del establecimiento de categorías de representaciones celulares. Básicamente corresponden a membrana y núcleo como estructuras claramente reconocibles y, de forma más imprecisa, otras estructuras perceptibles que podrian ser desde inclusiones y el retículo endoplasmático hasta bacterias superficiales. 
Resumiendo lo indicado hasta aquí, se puede señalar que los dibujos que realizan de sus observaciones se ajustan sensiblemente al aspecto de las muestras, mejorando en las representaciones a mayores aumentos y, especialmente, en células animales, aun cuando resultan irreconocibles en muchos casos. Sin embargo, la percepción del contenido celular es bastante pobre, incluso a grandes aumentos, representando en la mitad de los casos sólo una parte de las estructuras visibles.

\section{DISCUSIÓN Y CONCLUSIONES}

La interpretación que hacemos de los resultados del análisis de los dibujos de las muestras de epidermis de cebolla antes de la observación es la siguiente:

- A pesar de que según lo expuesto en otro trabajo (Jiménez y Díaz, 1993) parece que, en general, estos mismos estudiantes no poseen una gran destreza para la realizacion de dibujos, creemos que es patente el escaso conocimiento que manifiestan, en sus dibujos, del aspecto, forma de las células y de las estructuras celulares visibles de la epidermis de cebolla, en este tipo de prácticas. Sólo podríamos considerar aproximaciones válidas las correspondientes a representaciones de tipo $\mathrm{C} 3$, circulares, y $\mathrm{C} 4$, hexagonales, que suponen en conjunto el $32,7 \%$ en $1^{\circ}$ de BUP y el $28,2 \%$ en magisterio.

- Cuando desconocen la forma de las células, optan por una de dos soluciones: reproducen el aspecto macroscópico (tipo $\mathrm{Cl}$ ) o generalizan un rasgo atribuible (tipo C2).

- Son conscientes de que deben existir diferencias entre las imágenes microscópicas a diferentes aumentos y, en consecuencia, en los dibujos a menor aumento representan más rasgos macroscópicos (aros de cebolla), mientras que en los dibujos a mayores aumentos representan más la existencia de células, así como mayor número de elementos.

En cuanto a la realización de observaciones microscópicas como las realizadas por los estudiantes de los niveles considerados, los resultados comentados muestran que existen dificultades en el desarrollo de la tarea. Las razones pira cstas dificultades pueden ser de tipo actitudinal, técricas o dependientes de las destrezas de observación que posea el estudiante.

- I as razones actitudinales, fundamentalmente falta de interés en la actividad que están desarrollando y en la realización, en nuestro caso, de un dibujo, llevan a que el dibujo sea hecho de forma superficial, rápidamente, sobre la marcha, para cumplir con el menor esfuerzo posible con una tarea. Podrían justificarse así, pero sólo en cierta medida, los altos porcentajes de representaciones incorrectas o pobres, como las indicadas para ideas previas de epidermis de cebolla, Cl «irregulares», y el bajo número de elementos plasmados en los dibujos correspondientes y también las observaciones de muestras de epidermis de cebolla $\mathrm{OC} 1$, «irregulares», de epidermis de lirio OL1, «líneas paralelas», y OL2, «rectangulares o romboidales» y, en el caso del cpitelio bucal, a las representaciones OE2, "circulares», en las que no aparece nada más que la membrana y sobre todo las OE5, «otras».

- Otras causas podrían estar relacionadas con destrezas técnicas, tanto en la obtención de la muestra como en la realización de la preparación en la iluminación y el enfoque:

- Muestras deficientes: Tal es el caso de dibujos realizados a partir de la observación de una muestra de epidermis de cebolla o de hoja de lirio defectuosamente desprendida, que corresponden a algunos casos de las categorías que hemos denominado OCl y OLI.

- Preparaciones defectuosas: Otro caso típico corresponde a preparaciones de epidermis de cebolla o epitelio bucal que se han secado o en las que han quedado grandes burbujas de aire, como algunos dibujos de la categoría OC2, con aspecto de «muro», en cebolla o del tipo OEl de epitelio. Una tinción deficiente puede impedir la observación de las estructuras celulares e incluso el diferenciar adecuadamente las células individualmente, como en el caso del epitelio bucal, las representaciones $\mathrm{OE5}$, «otros», que resultan irreconocibles. La suciedad de los portaobjetos y cubreobjetos es otro de los factores a tener en cuenta.

- Iluminación y enfoque inadecuados: La iluminación excesiva, frecuente en las observaciones realizadas por estudiantes, podría ser una de las causas de escasa percepción de las estructuras celulares, concretamente en el caso de la epidermis de cebolla a $\times 400$ aumentos, y de las representaciones de estomas OEL2 y OEL3. El enfoque inadecuado, sobre la superficie del cubreobje tos probablemente sea la responsable de algunos de los dibujos que hemos incluido en las categorías OC1, OL6 y OE5.

- Las otras causas son las correspondientes a las destrezas de observación del estudiante. No todo el mundo tiene la misma capacidad de interpretar imágenes, y no todas las imágenes se interpretan con la misma facilidad. En la interpretación de imágenes pueden considerarse:

- Capacidad de reconocer estructuras cuando cambia la orientación: Se trata de una destreza que, según MacNab y Johnstone (1990), es dependiente del desarrollo y maduración y que se controla a partir de los 17-18 años, y la poseen del orden del $25 \%$ de los estudiantes de 15 años. Sin ser especialmente relevante, no cabe duda de que puede dificultarse la interpretación de una preparación como las consideradas si además inciden uno o más de los factores técnicos señalados. Podría tratarse de la razón por la que la disposición lateral de los núcleos es muy raramente representada en las observaciones de epidermis de cebolla, al no aparecer con su típico aspecto circular central en la célula. 
- Habilidad para discernir una figura oculta en un fondo distractor: Se trata de un estilo cognitivo que MacNab, Hansell y Johnstone (1991) encuentran relacionado con el bagaje de conocimientos biológicos que se posea, de tal forma que cuanto mayor sea éste mejor será la técnica para desensamblar imágenes. Según estos autores, los individuos "dependientes del campo" presentan unos niveles bajos de esta destreza, y generalmente se encaminan hacia áreas de conocimiento distintas de la biología, caso de la mayoría de los estudiantes de magisterio, lo que justificaría las dificultades para identificar células y estructuras que presenta este grupo. Concretamente en las muestras de epidermis vegetales, que deben ser desprendidas de los parénquimas subyacentes, se complica la interpretación al arrastrar adhericias células o fragmentos de células de capas inferiores, máxime en casos de tinciones defectuosas, como ya se indicó entre las causas técnicas. Por el contrario, en las muestras de epitelio bucal, el hecho de que las células aparezcan frecuentemente aisladas facilitaría su reconocimiento y descripción; este caso es excepcional, ya que, a pesar de lo que acabamos de senalar, estamos de acuerdo con Lucas (1969) en que ofrece mayor dificultad la interpretación de observaciones de tejidos animales compactos, estudiados en cortes histológicos, que los tejidos vegetales.

- Destrezas analíticas: La abstracción de información relevante para agrupar rasgos que son similares pero no idénticos y, en su caso, usarlos en una nueva situación, se desarrolla especialmente entre los 13 y los 16 años según MacNab, Hansell y Johnstone (1991); consiguientemente ello podría impedir que estudiantes de $1^{\circ}$ de BUP identificaran y representaran formas y estructuras celulares, al carecer de una idea previa suficientemente adecuada; en los demás niveles estas destrezas deberían estar desarrolladas. El modelo o imagen mental de célula que poseen los estudiantes considerados (Jiménez y Díaz, 1993) corresponde básicamente a una célula epitelial pavimentosa, lo que justificaría, junto con lo ya señalado, una mejor representación de este tipo celular.

- Características de las imágenes: En cierta medida, los rasgos de una imagen pueden causar una dificuitad de interpretación. Los contornos de las células, por analogía con los límites de los dibujos para los que Reid (1990a) ha señalado las dificultades de interpretación cuando son ambiguos, que no aparecen bien marcados y reconocibles, pueden dificultar la interpretación de imágenes microscópicas de las muestras, como ya se indicó entre los factores técnicos. Otras características de la imagen que afectan a la obtención de información de aquélla, son la complejidad que tiene y lo que destaque sobre su fondo. La información que se extrae de una imagen decrece a partir de cierto grado de complejidad (Reid y Miller, 1980). Creemos que por estas razones los estudiantes realizaron mejores representaciones de las células del epitelio bucal que del resto de las muestras, ya que la aparición en el campo visual de una única célula o unas pocas próximas e individualizadas simplifica notablemente la detección de su morfologia y eI reconocimiento de sus estructuras, lo que, obviamente, no es generalizable a todos los tejidos animales; en el caso de las células vegetales, la existencia de una patente pared celular, que las rodea tridimensionalmente y que se percibe en planos superpuestos con mayor o menor claridad, junto con el hecho aparente de ser compartida por células contiguas, dificultaría la percepción de la forma. El contenido celular aparecería, incluso con tinción, marcadamente homogéneo y, en consecuencia, no se percibirían fácilmente sus estructuras.

Como consideraciones finales, señalamos la necesidad, en nuestra opinión, de que en la realización de actividades de biología, como son las observaciones microscópicas, se tenga presente el nivel de las destrezas que poseen los estudiantes, desarrollándolas por metodologías, como Ias propuestas por Garvin y Boyd (1990) referentes a la interpretación de estructuras tridimensionales percibidas como imágenes microscópicas bidimensionales, y la realización de dibujos y diagramas que impliquen la interpretación, diferenciación y reconocimiento de diferentes estructuras celulares y tisulares, tanto observadas directamente por un microscopio como a partir de series fotográficas adecuadas, con una metodología similar a la utílizada por Wandersee (1992) para el reconocimiento de estructuras celulares en microfotografías electrónicas. También ha de tenerse presente que en la idea de los estudiantes sobre cómo es una célula (Jiménez y Díaz, 1993) aparecen entremezcladas distintas escalas y técnicas, microscopías ópticas y electrónicas, siendo necesario clarificarles tanto qué es lo que puede observarse como lo que no se podrá observar y cuál es el aspecto que presentará en cada caso. Se pueden reducir las dificultades en las tareas de observación microscópica debidas a causas técnicas, mostrando a los estudiantes los artefactos más frecuentes o el aspecto que ofrecen las muestras en tales casos, aspecto al que normalmente se presta poca atención.

Lo presentado aquí corresponde a aspectos parciales e iniciales de una investigación en curso, y algunas de las cuestiones aquí sugeridas se están estudiando con más detalle.

\section{AGRADECIMIENTOS}

Agradecemos a la Xunta de Galicia la financiación del proyecto XUGA $22701 \mathrm{~B} 91$, del cual es parte esta investigación; y a los docentes Cienfuegos, Garrido, Gonzâlez y Varela, así como a todos los estudiantes que participaron, su colaboración 


\section{REFERENCIAS BIBLIOGRÁFICAS}

CARAVITA, S. y TONUCCI, F. (1987). How children know biological structure-function relationships. II International Seminar on Misconceptions and Educational Strategies in Science and Mathematics, II, pp. 65-73. Cornell University, EEUU.

DÍAZ, J., JIMÉNEZ, M.P., CIENFUEGOS, E., GARRIDO, G., GONCALEZ ORTEGA, J. y VARELA, C. (1993). Imaxes das céltulas. Boletín das Ciencias, 16, pp. 200-204.

FUENTES MELERO, L. J.(1992). Reconocimiento de patrones, en Fernández Trespalacios, J.L. y Tudela Garmendia, P. (coor.), Atención y percepción. Madrid: Alhambra.

GARVIN, J.W. y BOYD, J.D. (1990). Skills in advanced Biology. Cheltenham: S. Thornes

GIORDAN, A. (1982). La enseñanza de las ciencias. Madrid: Siglo XXI.

GORDON,I.E. (1989). Theories of visual perception . Chichester: John Wiley.

HODSON, D. (1986). Rethinking the role and status of observation in science education. J. Curriculum Siudies, 18 (4), pp. $38 \mathrm{t}-396$.

JLMENEZ, M. P. y DfAZ, J. (1993). Drawing and slicing cells. III International Seminar on Misconceptions, Cornell University, EEUU.

LUCAS, A.M. (1969). Why Use the Microscope? The Australian Science Teahers Journal, 15(3), pp. 13-15. (Traducido al castellano en Alambique (1995), 6, pp. 89-92.)

LUNA BLANCO, M.D. (1992). Percepción visual de la forma y organización perceptual, en Fernández Trespalacios, J. L. y Tudela Garmendia, P. (coor.), Atención y percepción. Madrid: Alhambra.

MACNAB, W. y JOHNSTONE, A.H. (1990). Spatial skills which contribute to competence in the biological sciences. J. Biological Education, 24 (1), pp. 37-41.

MACNAB, W., HANSELL, M.H. y IOHNSTONE, A.H. (1991). Cognitive style and analytical ability and their relationship to competence in the biological sciences. J. Biological Education, 25 (2), pp. 135-139.

REID, D. J. (1984). The picture superiority effect and biologicaI education. J. Biological Education, 18 (I), pp. 29-36.

REID, D.J. (1990a) The role of pictures in learning biology: Part 1, perception and observation.J. Biological Education, 24 (3), pp. 161-172.

REID, D.J. (1990b). The role of pictures in learning biology: Part 2, picture-text processing. J. Biological Education, 24 (4), pp. 251-258.

REID, D.J. y MILLER, G.J.A. (1980). Pupils' perception of biological pictures and its implications for readability studies of biology textbooks. J. Biological Education, 14(1), pp. 59-69.

RUSSELL-GEBBETT, J. (1984). Pupils' perceptions of threedimensional structures in biology lessons. $J$. Biological Education, 18(3), pp. 220-226.

RUSSELL-GEBBETT, J. (1985). Skills and strategies- pupils' approaches to three-dimensional problems in biology. J. Biological Education, 19(4), pp. 293-298.

WANDERSEE, J.H. (1992). The graphic representation of biological knowledge: Integrating words and images. NATO Workshop. Ross Priory, Escocia, 14-16 de junio de 1992.

[Artículo recibido en febrero de 1995 y aceptado en junio de 1996.] 